\title{
Vertical distribution of aerosols over the east coast of India inferred from airborne LIDAR measurements
}

\author{
S. K. Satheesh ${ }^{1,2}$, V. Vinoj ${ }^{1}$, S. Suresh Babu ${ }^{3}$, K. Krishna Moorthy ${ }^{3}$, and Vijayakumar S. Nair ${ }^{3}$ \\ ${ }^{1}$ Centre for Atmospheric \& Oceanic Sciences, Indian Institute of Science, Bangalore 560 012, India \\ ${ }^{2}$ Divecha Centre for Climate Change, Indian Institute of Science, Bangalore 560 012, India \\ ${ }^{3}$ Space Physics Laboratory, Vikram Sarabhai Space Centre, Thiruvananthapuram 695022, India
}

Received: 27 January 2009 - Revised: 14 October 2009 - Accepted: 28 October 2009 - Published: 4 November 2009

\begin{abstract}
The information on altitude distribution of aerosols in the atmosphere is essential in assessing the impact of aerosol warming on thermal structure and stability of the atmosphere. In addition, aerosol altitude distribution is needed to address complex problems such as the radiative interaction of aerosols in the presence of clouds. With this objective, an extensive, multi-institutional and multi-platform field experiment (ICARB-Integrated Campaign for Aerosols, gases and Radiation Budget) was carried out under the Geosphere Biosphere Programme of the Indian Space Research Organization (ISRO-GBP) over continental India and adjoining oceans during March to May 2006. Here, we present airborne LIDAR measurements carried out over the east Coast of the India during the ICARB field campaign. An increase in aerosol extinction (scattering + absorption) was observed from the surface upwards with a maximum around 2 to $4 \mathrm{~km}$. Aerosol extinction at higher atmospheric layers $(>2 \mathrm{~km})$ was two to three times larger compared to that of the surface. A large fraction (75-85\%) of aerosol column optical depth was contributed by aerosols located above $1 \mathrm{~km}$. The aerosol layer heights (defined in this paper as the height at which the gradient in extinction coefficient changes sign) showed a gradual decrease with an increase in the offshore distance. A large fraction (60-75\%) of aerosol was found located above clouds indicating enhanced aerosol absorption above clouds. Our study implies that a detailed statistical evaluation of the temporal frequency and spatial extent of elevated aerosol layers is necessary to assess their significance to the climate. This is feasible using data from space-borne lidars such as CALIPSO, which fly in formation with other satellites like MODIS AQUA and MISR, as part of the A-Train constellation.
\end{abstract}

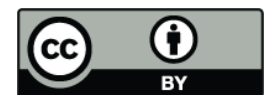

Correspondence to: S. K. Satheesh (satheesh@caos.iisc.ernet.in)
Keywords. Atmospheric composition and structure (Aerosols and particles; Pollution - urban and regional; Transmission and scattering of radiation)

\section{Introduction}

The radiative impact of aerosols still remains one of the largest sources of uncertainty in predicting future climate conditions (IPCC, 2001). The magnitude and sign of aerosol radiative impact depends on its chemical composition and the relative contribution of various chemical species, which constitute the aerosol (Andreae et al., 2005). The radiative forcing due to aerosols changes from region to region, depending on the relative strengths of various sources and sinks. However, when the amount of absorbing aerosols, such as soot, is significant, aerosol optical depth and chemical composition are not the only determinants of aerosol radiative effects, but the altitude of the aerosol layer, as well as the altitude and type of clouds also become important (Heintzenberg et al., 1997; Satheesh, 2002a; Seinfeld, 2008). Thus, the vertical distribution of aerosols assumes significance while addressing the radiative impact due to aerosols. It is interesting to note that atmospheric warming due to aerosols still remains a significant source of uncertainty, because most of the current estimates are largely based on model studies (Ramanathan et al., 2007). Moreover, the usual practice is to use measured aerosol properties at the surface and translate it to column properties to be used as input for radiation models by making assumptions about vertical profiles (Satheesh et al., 1999). The surface aerosol properties are often different from column aerosol properties because of the presence of distinct aerosol layers aloft (Ramanathan et al., 2001; Muller et al., 2001a, b). Thus, while translating surface to column aerosol properties based on the assumption of vertical profile

Published by Copernicus Publications on behalf of the European Geosciences Union. 
of aerosols can result in large errors (as much as a factor of two) (Satheesh, 2002a). Elevated layers of aerosols would occur as a consequence of strong thermal convection, which lifts aerosols near the ground to greater heights, where they might get entrained when the boundary layer collapses during the night or because of a reduction in convective activity (Stull, 1999; Satheesh et al., 2006). It could also occur due to the long-range transport of aerosols from other places (Niranjan et al., 2006, 2007a, b).

There have been several techniques to infer aerosol altitude structure and lidars have been the most popular. Ground based lidars are commonly used tools to obtain aerosol vertical structure at single point (Muller et al., 2001a, b, for example). Due to technical difficulties such as imperfect overlap between receiver and transmitter, most of the ground based lidars cannot see altitudes immediately above Earth's surface, which constitutes a major portion of Planetary Boundary Layer (PBL), which functions as an interface between Earth's surface and free troposphere (Palm et al., 1994). Airborne lidars, however, can provide a two-dimensional structure since they can view the planet from a height and can explore right down to the Earth's surface (McGill et al., 2003). In addition, air-borne lidars can provide two-dimensional cross section of the lower atmosphere with large spatial extent. Air-borne scanning lidars, on the other hand, can provide three-dimensional structures of aerosol plumes (Palm et al., 1994). Recently space-borne lidars (CALIPSO for example) have provided an excellent opportunity to infer global picture of aerosol vertical structure (Vaughan et al., 2004; McGill et al., 2007; Winker et al., 2007).

The information on the vertical distribution of aerosols is sparse over continental India. There exist a few recent studies on the vertical distribution of aerosols using aircraft based measurements over south central India (Moorthy et al., 2004; Gadhavi and Jayaraman, 2006). Continuous and campaign mode measurements of aerosol vertical distribution have been carried out at Visakhapatnam (a station located on the east coast of peninsular India) and Kharagpur (located at the vent of the out flow region from the Indo-Gangetic plains) respectively (Nirnajan et al., 2006, 2007a, b).

The measurements of aerosol vertical distribution over the oceanic regions adjacent to the Indian sub continent (Arabian Sea, tropical Indian Ocean and Bay of Bengal) are also scanty, excluding a few. During the Indian Ocean Experiment (INDOEX) there were a few aircraft measurements of aerosols and measurements of aerosol altitude distribution using island-based and ship-borne lidars (Muller et al., 2001a, b; Welton et al., 2002; Pelon et al., 2002). The seasonal cycle of aerosol vertical distribution was investigated by Muller et al. (2001a, b) over the Indian Ocean. Micro pulse lidar (MPL) systems were used to measure aerosol properties during the Indian Ocean Experiment (INDOEX) 1999 field phase. Measurements were made from two platforms: the NOAA ship R/V Ronald H. Brown, and the Kaashidhoo Climate Observatory (KCO) in the Maldives (Welton et al., 2002). The Mystere 20 (M20, IGN/CNRS/CNES/Meteo-France) participated in the INDOEX' 99 campaign from 25 February to 15 March 1999, for a total of 6 flights. The three-dimensional structure and the optical properties of the Indian pollution plume were investigated from airborne LIDAR and radiometric measurements over the Indian Ocean on three consecutive days (7, 8, and 9 March 1999) of the INDOEX'99 intensive field phase (Pelon et al., 2002).

In this paper, we report airborne LIDAR measurements of aerosol extinction profiles measured over the east coast of India. The measurements were carried out as part of the Integrated Campaign for Aerosols, gases, and Radiation Budget (ICARB) field campaign.

\section{ICARB field campaign}

During March-May 2006, an extensive, multi-institutional and multi-platform field experiment (ICARB - Integrated Campaign for Aerosols, gases and Radiation Budget) was carried out under the Geosphere Biosphere Programme of the Indian Space Research Organization (ISRO-GBP) over India. More than 100 investigators from 26 institutions participated in ICARB. The major objective of ICARB, one of the largest and most exhaustive field campaigns, ever conducted in the Indian region, was to assess the radiative impact of aerosols over the Indian landmass and the adjoining oceanic regions (Arabian Sea, northern Indian Ocean and Bay of Bengal) through intensive and simultaneous multi-platform observations. A network of ground based observatories (over the mainland and islands) (Fig. 1a), a dedicated ship cruise over the oceanic regions using a fully equipped research vessel, the R/V Sagar Kanya (Fig. 1b for cruise track) and altitude profiling over selected regions using an instrumented aircraft (flight tracks marked in green in Fig. 1b) together with balloon sondes formed the three segments (namely, the land segment, the ocean segment, and the air segment) of this integrated experiment (see Moorthy et al., 2008, for details).

The air segment of ICARB was executed using the aircraft of the National Remote Sensing Agency (NRSA) at Hyderabad (India), which dedicated one of its propeller aircraft (Beechcraft 20) to ICARB. The sorties were carried out from five bases - two each on the east (Bhubaneswar $\left(20.23^{\circ} \mathrm{N}, 85.82^{\circ} \mathrm{E}\right)$ and Chennai $\left.\left(13.2^{\circ} \mathrm{N}, 80.03^{\circ} \mathrm{E}\right)\right)$ and west coasts (Trivandrum $\left(8.5^{\circ} \mathrm{N}, 77^{\circ} \mathrm{E}\right)$ and Goa $\left(15.5^{\circ} \mathrm{N}\right.$, $73.8^{\circ} \mathrm{E}$ )) of India and one from the interior continent (Hyderabad $\left(18.05^{\circ} \mathrm{N}, 78.3^{\circ} \mathrm{E}\right)$, central India). In addition, groundbased lidar measurements were carried out from an urban site, Bangalore $\left(13.02^{\circ} \mathrm{N}, 77.5^{\circ} \mathrm{E}\right)$, in southern India. The sorties from each base were carried out in close co-ordination with the network of ground observatories and cruise operation over the adjoining oceans so that complementary near simultaneous surface measurements could be made around the period and location of the airborne measurements. The 
sorties were planned to be as close as possible to the $\mathrm{R} / \mathrm{V}$ Sagar Kanya tracks in the adjoining oceanic region. Airborne lidar measurements were not carried out from Goa due to logistic reasons as well as bad weather. Lidar profiles obtained at TVM and HYD have been reported in Satheesh et al. (2009) and hence are not repeated here. The airborne lidar measurements carried out over east coast of India (BBR and $\mathrm{CHN}$ ) and Bay of Bengal is the subject matter of this paper. Readers may note that even though aircraft covered only a small part of Bay of Bengal (BoB), by considering the fact that no prior information is available over BoB, we make attempt to extrapolate results from these campaign mode measurements to a more regional scale.

\section{Measurement location and meteorological features}

The Bay of Bengal (BoB) is a small oceanic region, surrounded by landmasses with distinct natural and anthropogenic activities. The Bay of Bengal region is similar to that of the Mediterranean Sea as both are severely affected by aerosols from a variety of natural and anthropogenic aerosol sources from the surrounding continents (Dulac and Chazette, 2003). These, along with the seasonally changing air mass types, make this region rather complex from the perspective of aerosols and their radiative impact. Prior to 2001, measurements of aerosols over the Bay of Bengal were nonexistent. In recent years, there have been a few efforts to understand aerosols over this region as part of various experimental campaigns (Satheesh, 2002b; Moorthy et al., 2003). In addition, extended aerosol observations commenced over the Bay of Bengal as part of ISRO-GBP with regular measurements of aerosol spectral optical depths using a multiwavelength radiometer (MWR) along with many other near surface aerosol measurements from an island location, Port Blair $\left(12^{\circ} \mathrm{N}, 92^{\circ} \mathrm{E}\right)$ (Moorthy et al., 2003). Still, the Bay of Bengal is one of the least explored regions from an aerosol perspective.

Oceanic regions adjacent to India are influenced by two contrasting air masses associated with the Asian monsoon system (Asnani, 1993; Krishnamurti et al., 1998). During the winter monsoon (November to March), the winds over the Arabian Sea and Indian Ocean are mainly weak, northeasterly or northerly. This implies that during the winter monsoon, winds carry aerosols from the Indian subcontinent to adjacent oceanic regions (Satheesh et al., 1999). From March onwards, winds start to shift in direction from the northeast to the northwest. By April, the winds become northwesterly and westerly and this continues until October. The monsoon rain usually starts by June and continues till August. A detailed analysis of the wind pattern in the Arabian Sea and Indian Ocean is reported elsewhere (Krishnamurti et al., 1998; Moorthy and Satheesh, 2000).

The synoptic meteorological conditions over the Bay of Bengal (BoB) are somewhat different from that over the Ara-
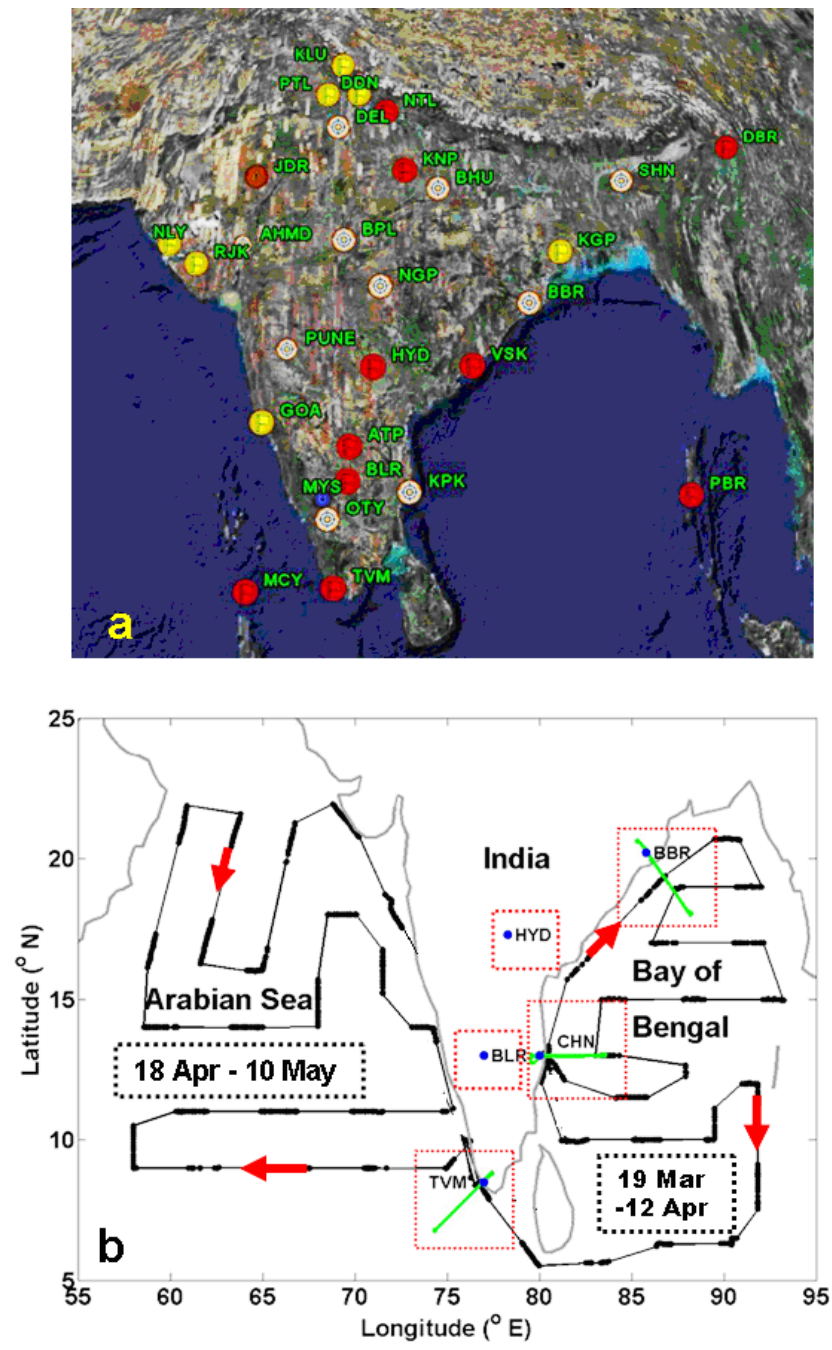

Fig. 1. (a) Network of ground based observatories (over the mainland and islands) (b) Cruise track of R/V Sagar Kanya with flight tracks of instrumented aircraft marked as green lines.

bian Sea or the Indian Ocean (Das, 1986; Asnani, 1993). Satheesh et al. (2006a) have provided a detailed analysis of air mass trajectories over $\mathrm{BoB}$, which indicated that at the $500 \mathrm{~m} \mathrm{level}$, about $68 \%$ (75\% at $1500 \mathrm{~m}$ and $79 \%$ at $2500 \mathrm{~m})$ of the time air masses influencing the northern BoB are from the east coast/central India, $14 \%(17 \%$ at $1500 \mathrm{~m}$ and $14 \%$ at $2500 \mathrm{~m}$ ) from east Asia/China and $18 \%(8 \%$ at $1500 \mathrm{~m}$ and $7 \%$ at $2500 \mathrm{~m}$ ) from the oceanic regions to the south. This study shows that the BoB region is influenced mostly by advection across the Indo Gangetic Plains (IGP) going as far back as West Asia (Iran, Afghanistan, Saudi Arabia) (see also Satheesh et al., 2009). 


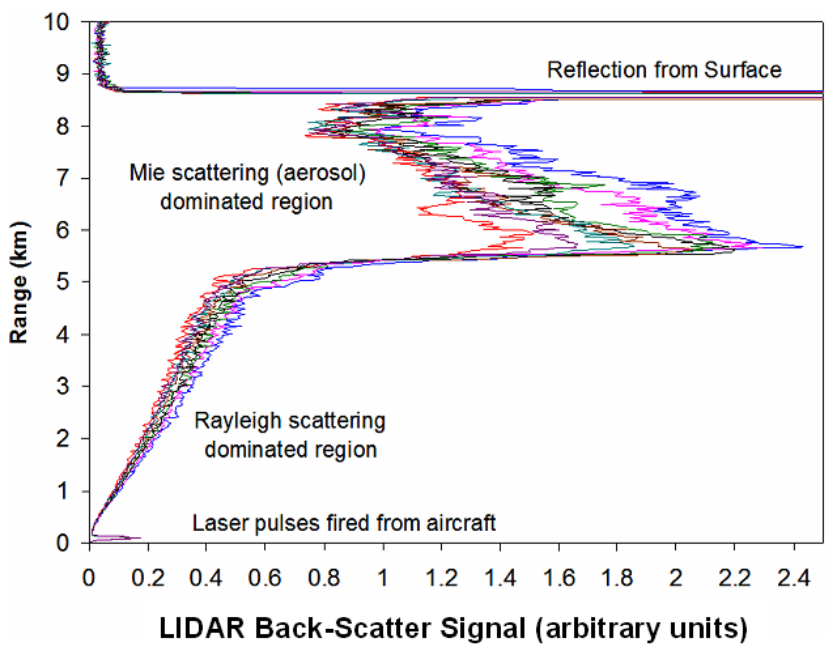

Fig. 2. Examples of range corrected LIDAR back-scatter (in arbitrary units) profiles. The signal is plotted in raw form so that the value of range zero represents aircraft location $(\sim 8 \mathrm{~km})$. The increase in back-scatter close to lidar is due to the poor overlap, which was corrected during data analysis.

\section{Micro Pulse Lidar (MPL), data and analysis}

The micro pulse lidar (model MPL1000 of Science and Engineering Services Inc., USA) uses an AlGaAs diode pumped Nd-YLF laser, converting the primary radiation at $1047 \mathrm{~nm}$ to its second harmonic at $523.5 \mathrm{~nm}$, at a pulse energy of $10 \mu \mathrm{J}$ and a pulse repetition frequency (PRF) of $2.5 \mathrm{kHz}$ (specifications are provided in Table 1). A Schmidt-Cassegrain telescope $(20 \mathrm{~cm}$ diameter) is used for transmission and reception, in a coaxial, collocated configuration making the MPL a very compact and sturdy system for field operations. The receiver uses a silicon avalanche photodiode (Si-APD) in the photon counting mode and this provides higher quantum efficiency (40-50\%) than the photo multiplier tube (PMT) based systems. More details about the MPL including the overlap correction (arises due to the imperfect overlap of laser beam with receiver field of view) procedure are provided elsewhere (Satheesh et al., 2006b). The MPL was fixed upside down in the aircraft. The optical flat window of the aircraft meant for survey operations provided the ideal window for lidar operations. A few examples of range corrected LIDAR backscatter (in arbitrary units) are shown in Fig. 2. The signal is plotted in raw form so that the value of range zero represents the aircraft location $(\sim 8 \mathrm{~km})$. The increase in back-scatter close to the lidar is due to the poor overlap (overlap in our case is close to 1 at around $1.4 \mathrm{~km}$ ), which was corrected following Satheesh et al. (2006b).

Although MPL used a coaxial geometry and the transmitting laser beam overlaps with receiver field of view almost perfectly, there is certain range within which the scattered radiation is not completely covered by the detector field-ofview. For near surface (when operating from ground) fea-
Table 1. Specifications of MPL 1000.

\begin{tabular}{ll}
\hline Laser & Diode pumped Nd-YLF \\
Wavelength & $523.5 \mathrm{~nm}$ \\
FOV & $50 \mu \mathrm{rad}$ \\
Frequency & $2500 \mathrm{~Hz}$ \\
Telescope & Schmid-Cassegraian $(20 \mathrm{~cm})$ \\
Detector & Silicon Avalanche Photodiode (Si APD) \\
Range resolution & $30 \mathrm{~m}$ (bin width 200 ns) \\
\hline
\end{tabular}

tures, this imperfect overlap needs to be corrected. Even though the manufacturers provide a geometrical formula for the overlap correction, in this study we have streamed the laser horizontally during relatively clean atmospheric conditions. Assuming horizontal homogeneity, the range corrected back-scatter (signal multiplied by $R^{2}$ where $R$ is the range) should be uniform if overlap is perfect. The changes in the backscatter signal from this are attributed to incomplete overlap. While deriving overlap function experimentally, the horizontal homogeneity was ensured by making measurements of column optical depth using Microtops sun photometer (Solar Light Inc., USA) in a mobile platform along the path length. The theoretical overlap function is estimated using a geometrical formula (manufacturer supplied), which contain information regarding optics used in the lidar. However, overlap function changes from one system to another. The theoretical overlap function need not agree with experimentally derived function as the theoretical overlap function is not realistic as far as each lidar system is concerned. Experimentally derived overlap function in this study has shown that the overlap correction is significant below a range of $1 \mathrm{~km}$. Overlap corrected signal is obtained by dividing the signal with overlap function.

For the analysis of MPL data, we have followed a particulate-free zone approach described by Kovalev and Eichinger (2004) and the procedure is provided elsewhere (Satheesh et al., 2006b). This is a modified approach originally proposed by Fernald (1984). This approach is based on the following principal elements (a) the molecular extinction profile is known (for e.g., from standard atmosphere models) (b) a priori information is used to specify the boundary value of the particulate extinction coefficient at a specific range within the measured region. In this study we have taken the aerosol extinction to be insignificant (particulatefree zone) at an altitude of $8 \mathrm{~km}$ (where the normalized backscatter value is four orders of magnitude smaller compared to that at the surface) and it has been used as the boundary value.

The Lidar backscattered signal undergoes several corrections before any useful information is retrieved. The corrections include (a) dead time correction (b) background correction (c) after pulse correction and (d) overlap correction. These are described in Spinhirne (1993). 
The Lidar signal $P(r)$ at the range $r$ for a two component atmosphere is given as,

$$
\begin{aligned}
P(r)= & \frac{C_{o} T_{o}^{2} \prod_{p}}{r^{2}}\left[\kappa_{p}(r)+a \kappa_{m}(r)\right] \\
& \times \exp \left\{-2 \int_{r_{o}}^{r}\left[\kappa_{p}(r)+\kappa_{m}(r)\right] d r\right\}
\end{aligned}
$$

Where $C_{o}$ is a constant; $T_{o}^{2}$ is the two way atmospheric transmittance over the incomplete over lap zone from $r=0$ to $r=r_{o}$; and $\prod_{p}$ is the particulate back scatter to extinction coefficient ratio (assumed range independent). The terms $\kappa_{p}(r)$ and $\kappa_{m}(r)$ are the particulate and molecular extinction coefficients at range $r$, respectively. Both these terms are unknowns in the lidar equation. The molecular absorption in the lidar operating range is assumed to be negligible and hence the extinction by molecules is mostly due to molecular scattering, then, $\kappa_{m}(r)=\beta_{m}(r)$, where $\beta_{m}(r)$ is the molecular scattering coefficient. The molecular backscatter to extinction coefficient ratio is $3 / 8 \pi$ and the term $a$ in the above equation is the ratio $a=(3 / 8 \pi) / \prod_{p}$.

The analytical solution for the lidar equation used in the present study following Kovalev and Eichinger (2005) is given briefly below. The initial lidar equation is transformed to a form which can analytically be solved by using an initial transformation function of the form,

$Y(r)=\frac{1}{\prod_{p}} \exp \left[-2 \int_{r_{o}}^{r}(a-1) \beta_{m}(r) d r\right]$

The determination of the transformation function $Y(r)$ requires a priori knowledge of the molecular scattering coefficient profile $\beta_{m}(r)$ and the particular back scatter to extinction coefficient along the lidar search path. The extinction to back scatter ratio (lidar ratio) depending on atmospheric conditions can be assumed to be either range independent or dependent. In the present study, due to the unavailability of detailed aerosol vertical properties, we have assumed a range independent extinction to back scatter ratio. It may be noted that the lidar ratio in the marine layer on average is lower (around $20 \mathrm{sr}$ at $532 \mathrm{~nm}$ ) compared to the lidar ratio in the lofted layer (around $60 \mathrm{sr}$ at $532 \mathrm{~nm}$ ). A sensitivity analysis based on this show that assuming range independent lidar ratio can lead to an uncertainty in the derived extinction coefficients up to around $12 \%$.

Under transformation the original equation transforms to a form,

$Z(r)=P(r) Y(r) r^{2}$

where,

$Z(r)=C_{o} T_{o}^{2} \kappa_{w}(r) \exp \left[-2 \int_{r_{o}}^{r} \kappa_{w}(r) d r\right]$

$\kappa_{w}(r)$ is the weighted extinction coefficient of the form,

$\kappa_{w}(r)=\kappa_{p}(r)+a \beta_{m}(r)$
The integration of $Z(r)$ over the range from $r_{o}$ to $r$ gives

$\int_{r_{o}}^{r} Z(r) d r=\frac{C_{o} T_{o}^{2}}{2}\left\{1-\exp \left[-2 \int_{r_{o}}^{r} \kappa_{w}(r) d r\right]\right\}$

The boundary point solution can be applied if there exists a point in the lidar range $r_{b}$ where the numerical value of $\kappa_{w}\left(r_{b}\right)$ is known or can be specified a priori. This information along with Eqs. (5) and (3) can be used to obtain the boundary point solution which is given by,

$\kappa_{w}(r)=\frac{Z(r)}{\frac{Z\left(r_{b}\right)}{\kappa_{w}\left(r_{b}\right)}+2 \int_{r_{o}}^{r_{b}} Z(r) d r}$

Once the weighted extinction coefficient profile is obtained, the numerical value of the particulate extinction coefficient profile can be calculated by using Eq. (5) as

$\kappa_{p}(r)=\kappa_{w}(r)-a \beta_{m}(r)$

Equation (7) can be used both for far and near-end solutions depending on the location selected for the boundary point " $r_{b}$ ". If $r_{b}<r$, the near end solution is obtained; hence the summation in Eq. (7) is transformed into subtraction due to the reversal of the integration limits. In the ICARB lidar analysis, the cruising altitude of the aircraft $(\sim 8 \mathrm{~km}$ above ground level) has been assumed as the particulate free zone and hence the boundary point where, $\kappa_{p}(r)=0$.

Since MPL does not have an absolute calibration, the height integrated extinction coefficient (from lidar) was calibrated against column optical depth measured from R/V Sagar Kanya using a Microtops sun photometer (Solar Light Inc., USA) calibrated regularly at the Mauna Loa observatory, Hawaii. The locations of lidar measurements with respect to the ship track are also shown in Fig. 1b.

\section{$5 \quad$ Results and discussions}

Since the Bay of Bengal during pre-monsoon season is influenced by aerosols transported from Indian subcontinent and adjacent regions, we show the regional distribution of aerosol optical depth (AOD) at $550 \mathrm{~nm}$ obtained from MODIS TERRA for March and April 2006 in Fig. 3. Large AODs are seen over the Indo-Gangetic basin, northeast India, Myanmar and coastal India. Large AODs over coastal India are consistent with observations reported in Moorthy et al. (2005). They reported higher aerosol concentrations over the coastal regions of India compared to inland regions and attributed this to a higher population density in the coastal regions (more than $70 \%$ of the population lives in the coastal belt). To examine the regions of biomass burning during the observation period, we show monthly maps of fire pixel counts (a measure of biomass burning) from MODIS TERRA data in Fig. 4. Fire pixel counts are estimated from infrared satellite radiance and represent the number of occurrences of high infrared emission from the surface (biomass 


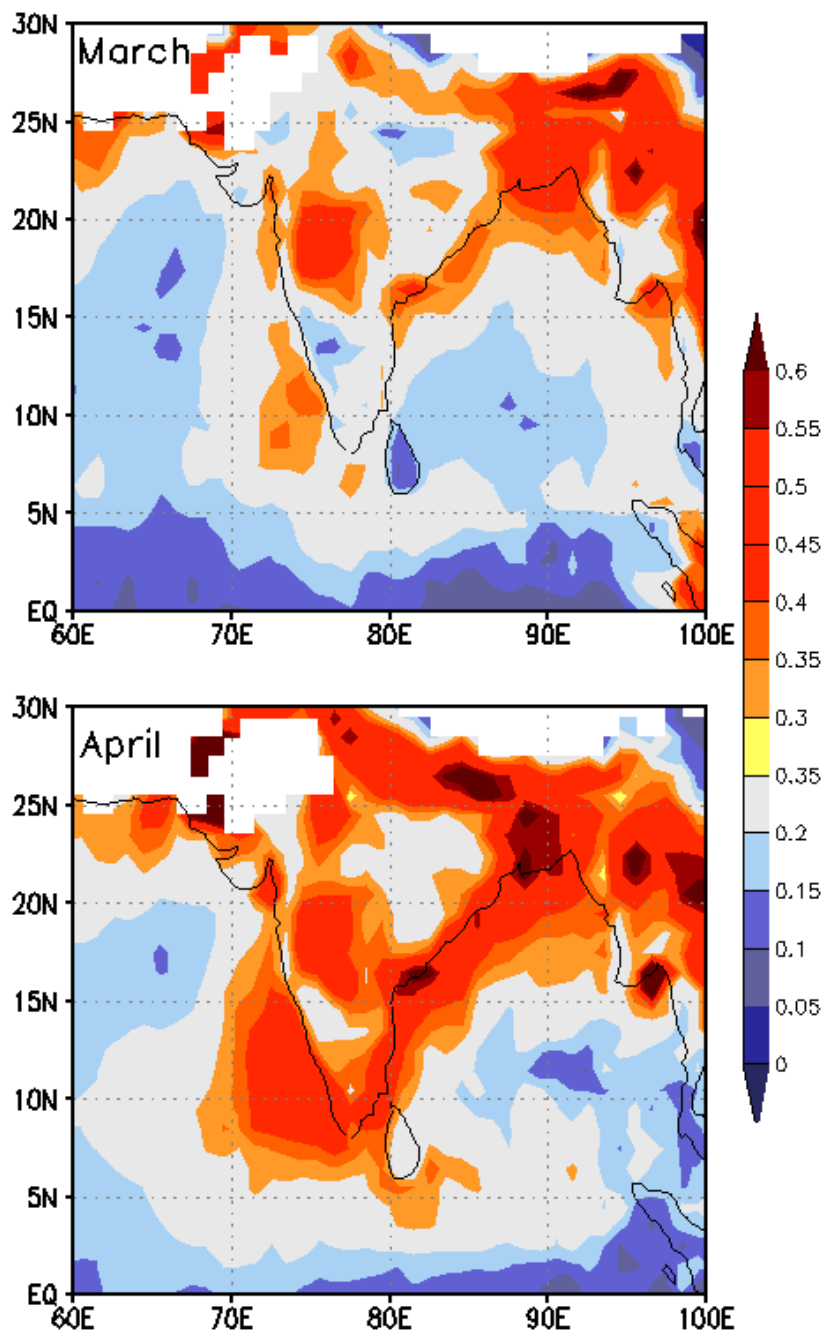

Fig. 3. Regional map of aerosol optical depth (MODIS at $550 \mathrm{~nm}$ channel) over India and adjacent continents during March and April 2006.

burning episodes). These maps show intense biomass burning activity over the Indo-Gangetic basin, northeast India and the Myanmar regions. This, in conjunction with features of meteorology discussed in Sect. 3, indicates substantial amount of carbonaceous aerosol transport to the Bay of Bengal.

Typical backscatter profiles obtained over ocean adjacent to Bhubaneswar (BBR) at various distance ranges from the coast are shown in Fig. 5. The representative vertical profiles of the extinction coefficient from airborne micro pulse lidar for 25 March 2006 at BBR and for 3 April 2006 at Chennai $(\mathrm{CHN})$ are shown in Fig. 6. The vertical profiles shown are averaged for various offshore distances $(<50,50-150,150$ $250 \mathrm{~km}$ ). Multiple aerosol layers, with a nearly three-fold increase in the aerosol extinction coefficient at higher levels of the atmosphere ( $\sim 2$ to $3 \mathrm{~km}$ ) compared to that of the surface, were observed in both locations. Multiple aerosol

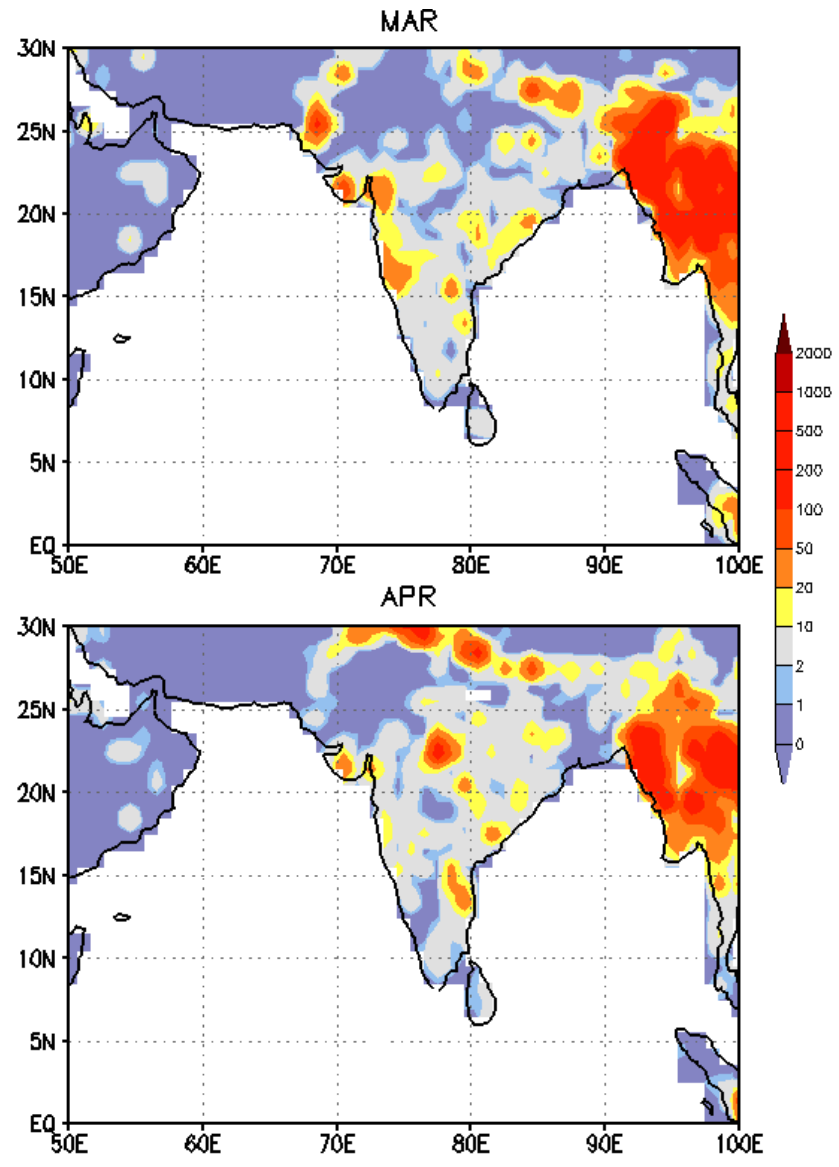

Fig. 4. Regional map of TERRA fire pixel count indicating biomass burning locations over India and adjacent continents during March and April 2006.

layers were reported earlier by several investigators. Muller et al. (2001a, b) from year-round measurements of aerosol profiles using six-wavelength lidar at Maldives reported multiple aerosol layers with a strong aerosol back-scatter up to a height of $4 \mathrm{~km}$. Pelon et al. (2002) using airborne lidar measurements over Indian Ocean reported two distinct aerosol layers, one below $1 \mathrm{~km}$ and another between 1 to $2 \mathrm{~km}$ of altitude. Welton et al. (2002) using micro pulse lidar observations onboard the NOAA ship R/V Ronald H. Brown reported two aerosol layers over the Arabian Sea (one below $1 \mathrm{~km}$ ) and a second layer between 2 to $3 \mathrm{~km}$. Niranjan et al. (2007a) have studied aerosol backscatter profiles obtained using a micro pulse lidar at Visakhapatnam, a station located on the east coast of peninsular India. They reported the presence of aerosol layers at higher altitudes $(2-3 \mathrm{~km})$ during the months of March/April 2005 and 2006. Further examination of this aspect, using 7-day back trajectory analysis simultaneous with MODIS and ground based measurements, indicated that the possible origin of the layers could be from the Arabian region in $60 \%$ of the cases (Niranjan et al., 2007a). 

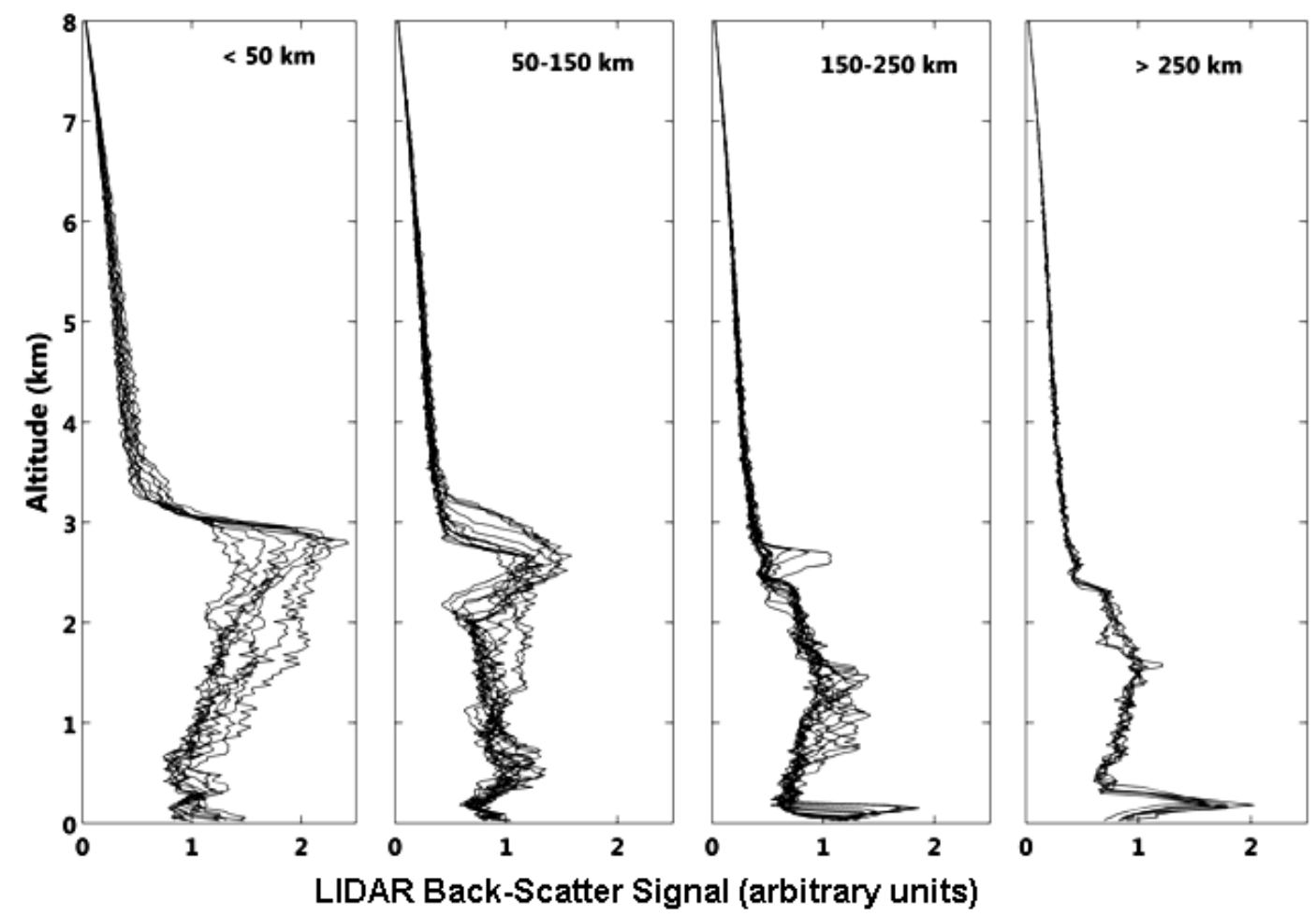

Fig. 5. Typical vertical profiles of lidar back-scatter signal from the air-borne lidar.
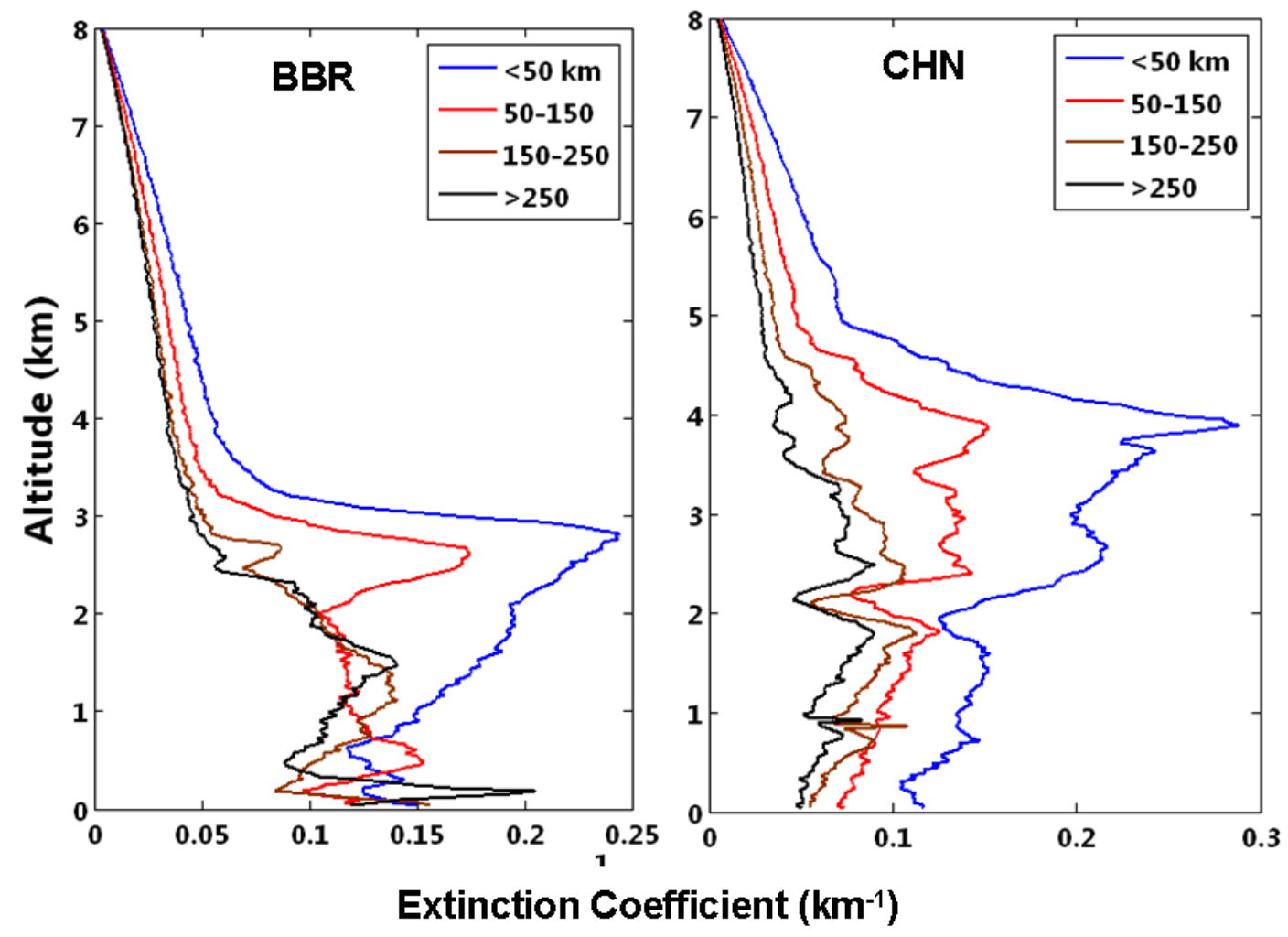

Fig. 6. Typical vertical profiles of aerosol extinction coefficient derived from the air-borne lidar. Here, BBR represent Bhubaneswar and $\mathrm{CHN}$ represents Chennai respectively. 


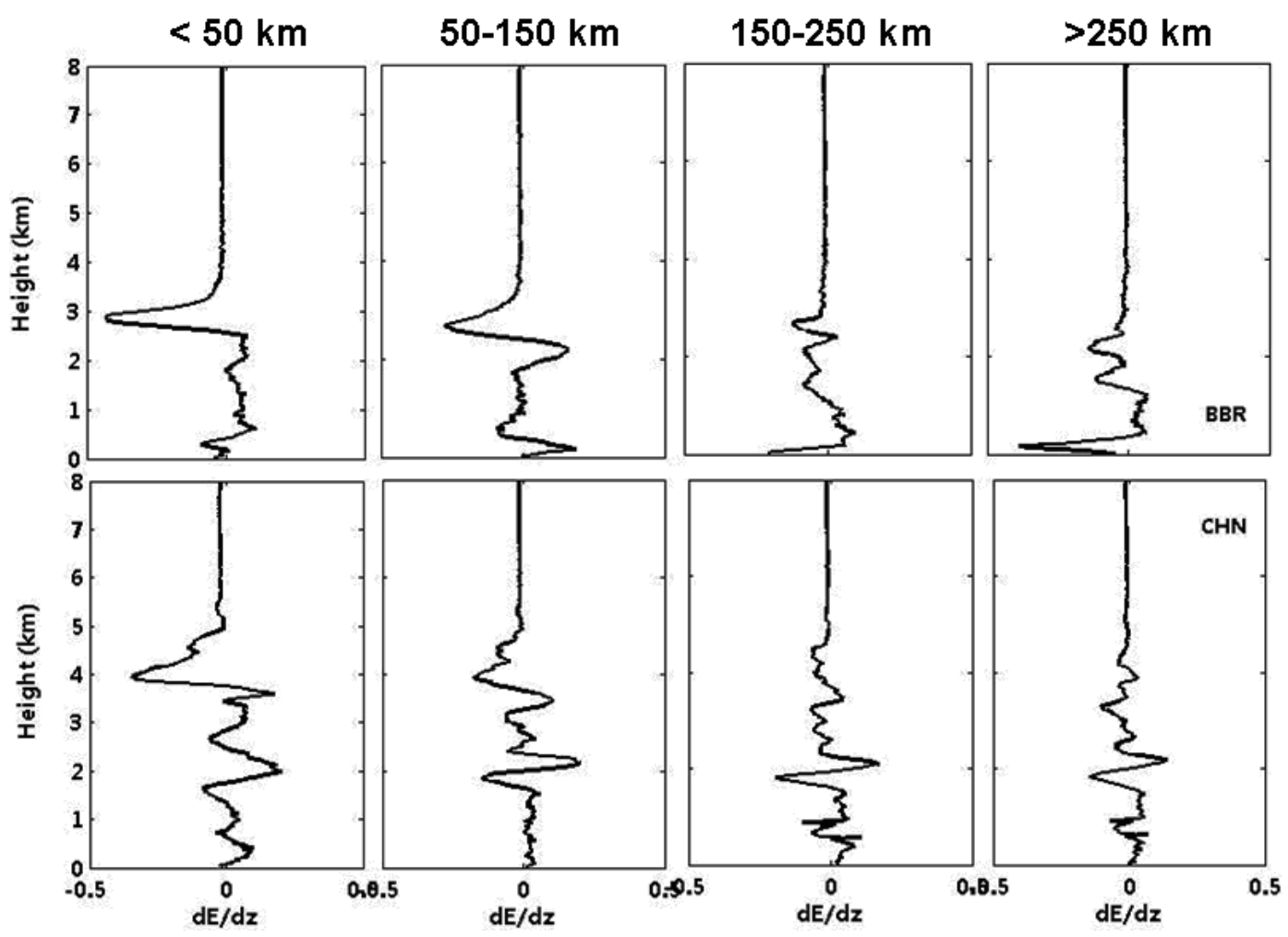

Fig. 7. Derivative of extinction coefficient profiles shown in Fig. 6.

Palm et al. (1994) using a scanning airborne lidar system over the coastal Atlantic Ocean have studied aerosols trapped within the marine boundary layer and observed aerosol layers at around $800 \mathrm{~m}$. Dulac and Chazette (2003) studied aerosol vertical distribution over the east Mediterranean using air borne lidar measurements. They found that the vertical structure of the lower atmosphere was complex, with a superposition of several turbid aerosol layers from the surface up to an altitude of about 2 to $4 \mathrm{~km}$. A clean freetroposphere was found only above $5 \mathrm{~km}$. Depolarization ratio measurements revealed three distinct aerosol layers with geographically varying thickness and categorized them into three distinct aerosol types. There are similarities between the Mediterranean Sea and the Bay of Bengal. The atmosphere over both is severely affected by aerosols from a variety of natural and anthropogenic continental sources.

Multi-wavelength global back-scatter experiment (GLOBE) lidar measurements over the Pacific Ocean revealed elevated aerosol layers between 3 and $5 \mathrm{~km}$, which are attributed to dust from Asia (Menzies et al., 2002). Based on an analysis of multi-wavelength back-scatter and back-scatter ratios, they inferred that the elevated dust was contaminated with anthropogenic aerosols. Using the Cloud Physics Lidar (CPL) onboard NASA's ER-2, King et al. (2003) observed elevated aerosol layers between 3 to $4 \mathrm{~km}$ altitudes over southern Africa during the dry biomass burning season. The back-scatter to extinction ratios esti- mated from the CPL were consistent with those expected for smoke (McGill et al., 2003). A Raman lidar, part of the European Aerosol Research Lidar Network (EARLINET) operated at Leipzig, Germany has shown Saharan dust layers up to an altitude of $6 \mathrm{~km}$ (Muller et al., 2003). Vertically resolved Angstrom wavelength exponents derived from multi-wavelength lidar profiles showed values as low as -0.2 in the center of the dust plume. Below $1000 \mathrm{~m}$, Angstrom exponents varied substantially in the range of 0.4 to 1.0. Sun photometer observations simultaneous with lidar have shown that $\sim 90 \%$ of optical depth (at $532 \mathrm{~nm}$ ) was contributed by a dust layer above $1000 \mathrm{~m}$. An elevated aerosol layer at an altitude of $4 \mathrm{~km}$ with a spatial extent of $>200 \mathrm{~km}$ was observed during airborne lidar measurements leeward of the European Alps and Apennine mountains (Nyeki et al., 2002). Detailed meteorological analysis suggested that mountain venting followed by advection was responsible for its formation.

Airborne lidar measurements (onboard the University of Washington's Convair-580 research aircraft) during the dry season over southern Africa (part of the southern African regional science initiative, SAFARI 2000) have revealed massive, thick and multiple aerosol layers extending well above $5 \mathrm{~km}$ (Schmid et al., 2003). Simultaneous measurements using airborne sun photometers showed steep spectral dependence of the aerosol extinction coefficient, indicating that elevated aerosol layers are constituted by sub 
micron aerosols such as biomass burning aerosols. During the Aerosol Recirculation and Rainfall Experiment (ARREX 1999) and Southern African Regional Science Initiative (SAFARI 2000) dry season experiments, a micropulse lidar $(523 \mathrm{~nm})$ instrument was operated at the Skukuza Airport in northeastern South Africa (Campbell et al., 2003). Their observations revealed persistent elevated aerosol layers over this region. During the Puerto Rico Dust Experiment (PRIDE), June-July 2000, Maring et al. (2003) measured aerosol properties over the tropical North Atlantic. They observed aerosols layers (from Sahara) aloft with dust loading exceeding $170 \mu \mathrm{g} \mathrm{m}^{-3}$. They also report substantial variability in the vertical distribution and small differences in the size distribution of dust between the marine boundary layer and Saharan aerosol layer (Maring et al., 2003). Lidar measurements of the vertical distribution of optical particle properties were performed in January 2006 in the frame of the dry season field experiment of the African Monsoon Multidisciplinary Analyses (AMMA) (Heese et al., 2008). The profiles showed varying dust layer in the lowermost troposphere during the whole period. Above the dust layer a broad layer of biomass burning aerosol reaching up to an altitude of $5 \mathrm{~km}$ was frequently observed with the extinction coefficient ranging from 0.2 to $0.4 \mathrm{~km}^{-1}$ at $355 \mathrm{~nm}$ (Heese et al., 2008). Measurements of the vertical distribution of aerosol extinction coefficient over West Africa during the Dust and Biomass-burning Aerosol Experiment (DABEX) are reported by Johnson et al. (2008). They have observed that mineral dust at low altitudes (up to $2 \mathrm{~km}$ ), and a mixture of biomass burning aerosol and dust at altitudes of $2-5 \mathrm{~km}$.

The aerosol layer heights defined in this paper was obtained by differentiating the extinction coefficient profiles and height at which gradient in extinction changes sign has been used as layer height. Derivative of extinction coefficient profiles are shown in Fig. 7. A gradual decrease in the aerosol layer height was observed with an increase in the offshore distance. To study the vertical structure of the atmosphere during the observation period, we examine the vertical profiles of atmospheric parameters in the regions of investigation using GPS sonde ascents from the ship located close to the locations of aerial measurements. In Fig. 8 we show the vertical profiles of potential temperature $(\theta \mathrm{K})$, relative humidity ( $\mathrm{RH} \%)$, horizontal wind speed $\left(\mathrm{U} \mathrm{m} \mathrm{s}^{-1}\right)$, and direction $\left(D^{\circ}\right)$, up to an altitude of $6 \mathrm{~km}$, derived from the balloon ascent data off Chennai (as representative) on 1 April 2006. Potential temperature is derived from temperature $(T)$ and pressure using the relation

$\theta_{z}=T *\left(P_{0} / P_{z}\right)^{0.286}$

where $P_{0}$ is the standard pressure and $P_{z}$ at an altitude $z$.

Two convectively unstable regions (where $\theta$ remains nearly height independent) exist, first from the ground to about $500 \mathrm{~m}$, and the other extending from $\sim 1$ to $3 \mathrm{~km}$, separated by a stable region in-between. Both these regions have

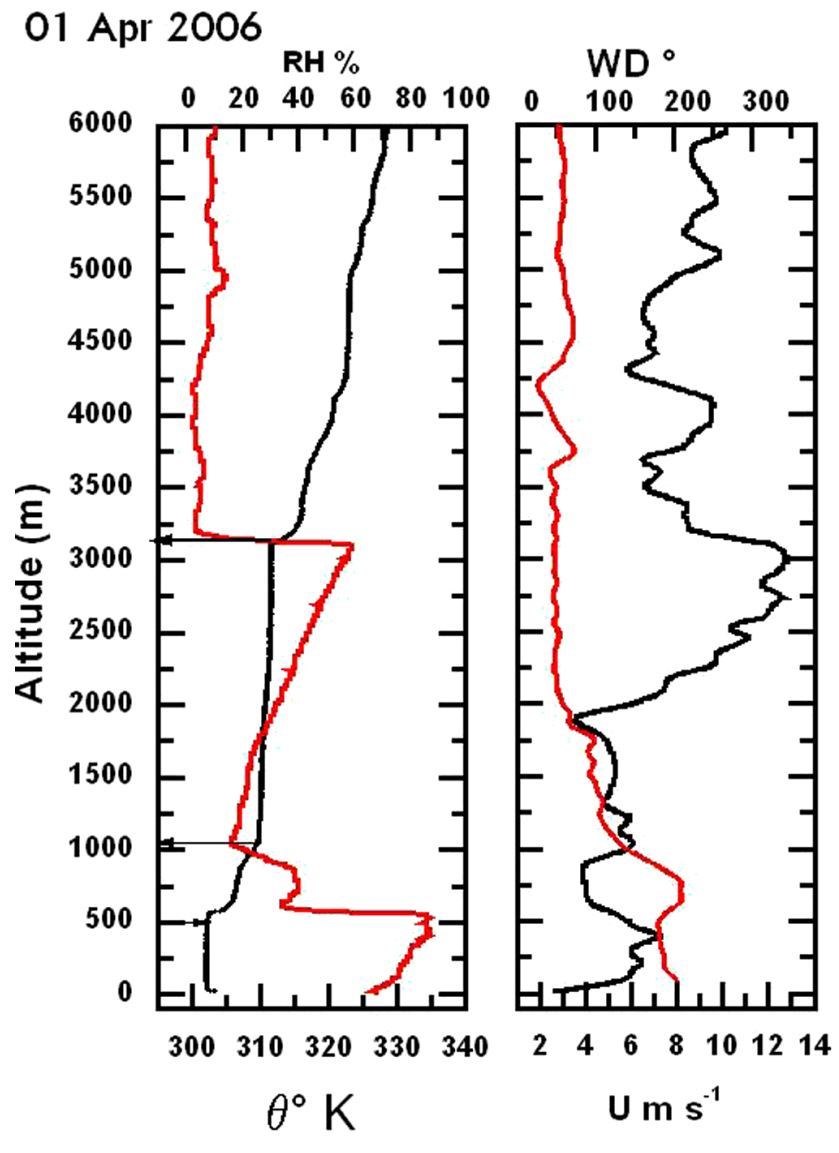

Fig. 8. Vertical profiles of atmospheric parameters such as potential temperature $(\theta \mathrm{K}$, black line), relative humidity (RH \%, red line), horizontal wind speed ( $\mathrm{U} \mathrm{m} \mathrm{s}^{-1}$, black line), and direction $\left(D^{\circ}\right.$, red line), up to an altitude of $6 \mathrm{~km}$, derived from the GPS sonde ascent data off Chennai.

strong winds (6 to $10 \mathrm{~m} \mathrm{~s}^{-1}$ ), the direction of which shifts from northeasterly near the surface to northerly at the higher levels. The stable layer topped at a $1 \mathrm{~km}$ altitude favours the long-range transport of aerosols and species in the higher level, to long distances, without entering the well-mixed region below.

The contribution of aerosols located in the first three kilometres to the column optical depth is shown in Fig. 9. Here, we integrated aerosol extinction coefficient up to 1,2 and $3 \mathrm{~km}$ respectively to obtain their contribution to column optical depth. A major fraction (75-85\%) of column optical depth appears contributed by aerosols located above $1 \mathrm{~km}$. A similar exercise was carried out to estimate the contribution of aerosols located above the cloud top and the results are shown in Fig. 10. We integrated aerosol extinction coefficient up to cloud top height to obtain their contribution to column optical depth. Here, cloud heights were obtained from MODIS onboard TERRA and AQUA satellites. Again, a major fraction of the aerosols are found located above the cloud top. 


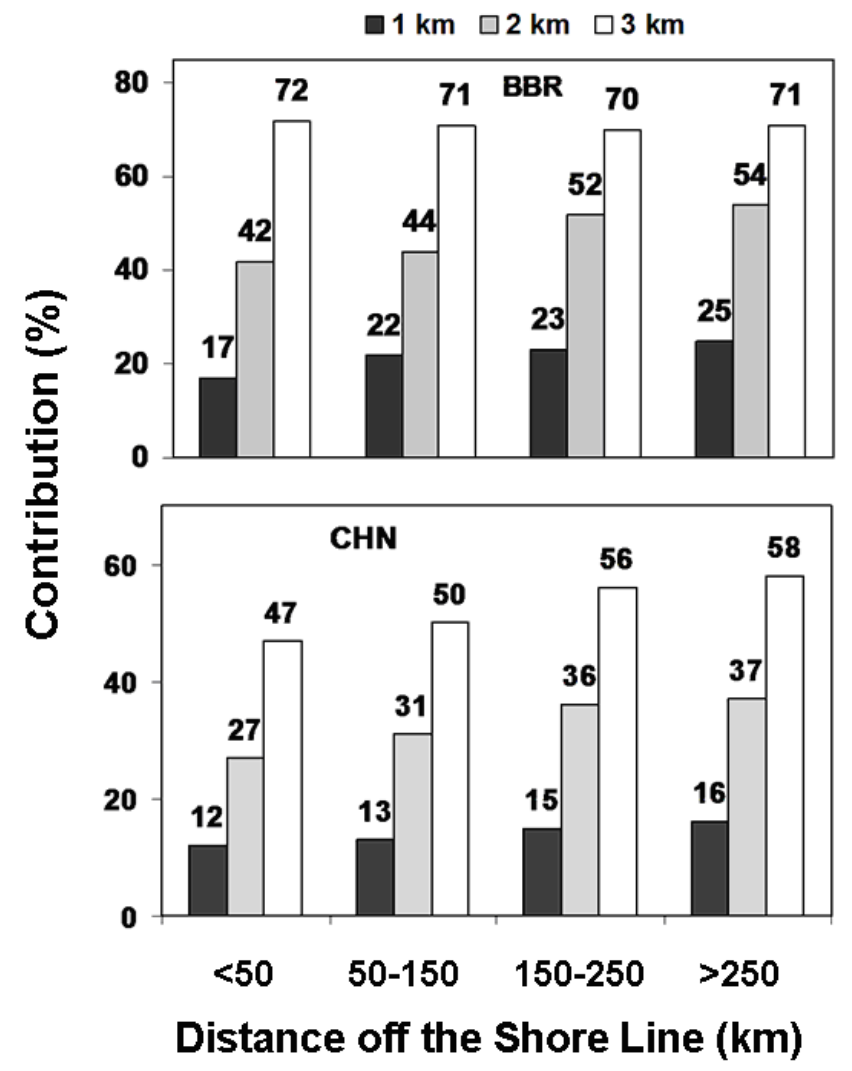

Fig. 9. Contribution of aerosols located in the first three kilometres to the column optical depth.

The fact that a major fraction of aerosol is located above the cloud top has implications while we address the climate impact of aerosols. Even in clear-sky conditions, the location of the aerosol layer with respect to ground or cloud is an important determinant of its warming potential. The consequent effect on atmospheric stability (which is an important factor in cloud formation processes) depends on whether warming takes place at the Earth's surface or above. The net atmospheric absorption caused by the presence of aerosols warms the layer and the resulting atmospheric heating rate is (Liou, 2002),

$\frac{\partial T}{\partial t}=\frac{g}{C_{p}} \frac{\Delta F}{\Delta p}$

where $\partial T / \partial t$ is the heating rate $\left(\mathrm{K} \mathrm{s}^{-1}\right), \boldsymbol{g}$ the acceleration caused by gravity, $\boldsymbol{C p}$ the specific heat capacity of air at constant pressure $\left(1006 \mathrm{~J} \mathrm{~kg}^{-1} \mathrm{~K}^{-1}\right), \Delta F$ the absorbed energy and $\boldsymbol{p}$ the atmospheric pressure, respectively. Equation (4) predicts that even in the case of well-mixed (with respect to height) aerosols, the highest heating rate takes place at a higher level above the ground, and not close to the ground ( $\Delta F$ is nearly constant for all layers for a well-mixed aerosol, while $\Delta p$ is much lower at the $3 \mathrm{~km}$ level compared to that near the surface). This underlines the importance of the ver-

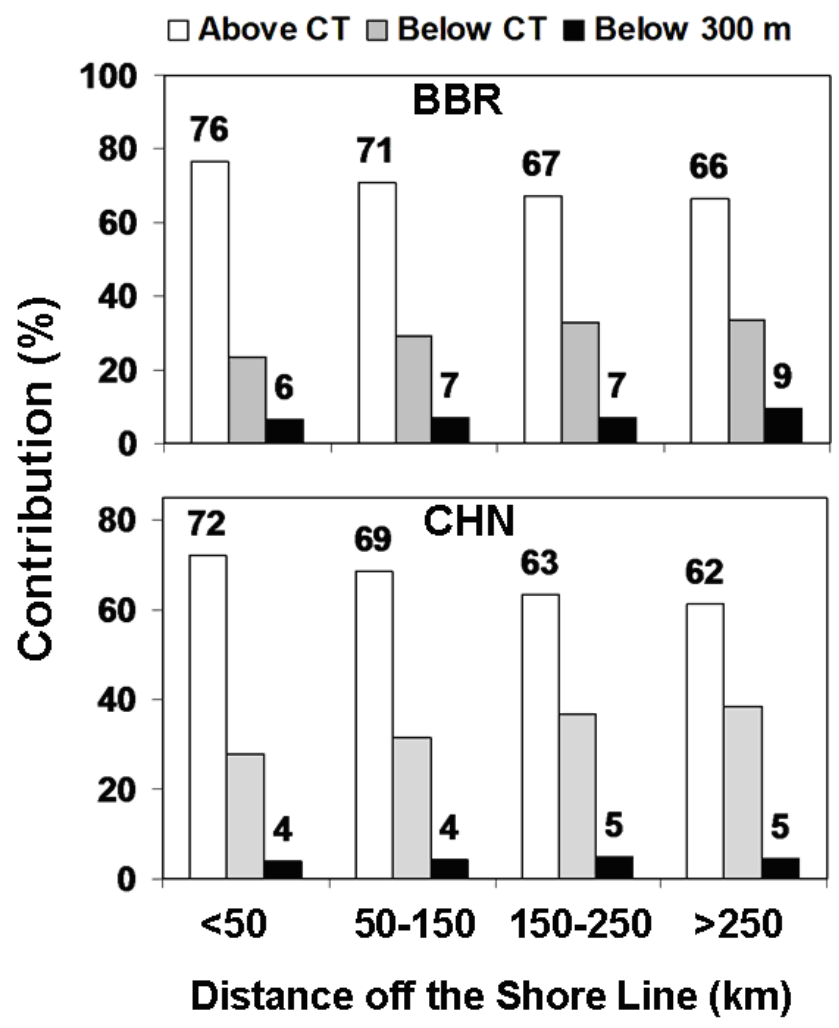

Fig. 10. Ccontribution of aerosols located above cloud top to column optical depth.

tical distribution of aerosols while addressing its interaction with radiation.

The layer extinction coefficient and contribution of $\mathrm{BC}$ to layer extinction are used to estimate downward and upward flux at several layer boundaries $(<4 \mathrm{~km})$ for "with" aerosol and "without" aerosol conditions. We have used a discrete ordinate radiative transfer model described by Ricchiazzi et al. (1998) for this purpose. The net fluxes (downward minus upward) due to aerosols at the layer boundaries were differenced to obtain the energy absorbed in that layer, from which the warming rate under clear-sky conditions (24-h average) are estimated. We find that the warming due to aerosol absorption is around $1.5 \mathrm{~K} /$ day. The aerosol-induced warming rates observed in our study are larger than those reported by Ramanathan et al. (2007) for Indian Ocean.

Multi-wavelength lidar measurements over the Pacific Ocean revealed elevated aerosol layers between 3 to $5 \mathrm{~km}$ and based on an analysis of multi-wavelength back-scatter coefficients and their ratios Menzies et al. (2002) inferred that the elevated dust is contaminated with anthropogenic aerosols. A Raman lidar operated at Leipzig, Germany, has shown Saharan dust layers up to an altitude of $6 \mathrm{~km}$ and $\sim 90 \%$ of aerosol optical depth (at $532 \mathrm{~nm}$ ) was contributed by a dust layer above $1000 \mathrm{~m}$. In our study, we found that $\sim 75$ to $85 \%$ of aerosol optical depth was contributed by aerosol above 
$1000 \mathrm{~m}$. Recent investigations have shown that when black carbon exists in a mixed state with other aerosols, the absorption increases substantially (by a factor of two to three) (Jacobson, 2000; Chandra et al., 2004). Scanning Electron Microscope (SEM) images of surface aerosol samples collected from southern India indicates the presence of 'mixed' aerosols (Satheesh et al., 2006c) and the present study indicates that a substantial fraction of these aerosols is located above the clouds. Optically thick clouds occurring below an aerosol layer effectively serve as a highly reflective background and enhance the absorption by aerosols above the clouds (Seinfeld, 2008). Thus the present results indicate extensive warming by aerosols above the clouds as also acknowledged in Satheesh et al. (2008) for central, southern continental India and the north Indian Ocean. If warming by elevated absorbing aerosols over coastal India is considerably greater, issues such as cloud "burn off" proposed by Ackerman et al. (2000) become increasingly relevant. Earlier investigation over the Indian Ocean by Satheesh and Ramanathan (2000) and Ramanathan et al. (2001) have demonstrated that the low-level trade cumulus clouds, north of the inter-tropical convergence zone (ITCZ), are embedded within the aerosol layer. This observation is important as our study shows a substantial fraction of aerosol above the clouds. The Bay of Bengal has a crucial role in the summer monsoon and it is still uncertain whether the strong aerosolinduced warming of the lower atmosphere can modify cloud formation processes.

Detailed information on the temporal frequency and spatial extent of elevated aerosol layers is necessary to assess their significance to the climate. This is feasible using data from space-borne lidars such as CALIPSO, which fly in formation with other satellites like MODIS AQUA and MISR, as part of A-Train.

\section{Conclusions}

1. Aerosol extinction was found to increase from surface upwards with a maximum in extinction between 2 and $4 \mathrm{~km}$.

2. Aerosol extinction at higher atmospheric layers $(>2 \mathrm{~km})$ was two to three times greater compared to that of the surface.

3. A large fraction (75-85\%) of aerosol column optical depth was found contributed by aerosols located above $1 \mathrm{~km}$.

4. Aerosol layer heights showed a gradual decrease with an increase in offshore distance.

5. A large fraction (60-75\%) of aerosol was found located above the clouds leading to enhanced aerosol absorption above the clouds.
6. Our study suggests the need for a detailed statistical evaluation of the temporal frequency and spatial extent of elevated aerosol layers, which is essential to assess their significance to climate.

Acknowledgements. This research work was carried out under the Integrated Campaign for Aerosols, gases, and Radiation Budget (ICARB) field campaign of ISRO-GBP and the authors thank V. Jayaraman and R. Sridharan for their support. The authors thank Department of Science and Technology, New Delhi for supporting the Micro Pulse Lidar (MPL) used in this work. Authors are grateful to K. Radhakrishnan, aircraft team (headed by K. Kalyanaraman and V. Raghu Venkataraman), Rasik Ravindra, and M. Sudhakar for their excellent cooperation and support through out the campaign. One of the authors (SKS) would like to thank Department of Science and Technology, New Delhi for the Swarna Jayanti Fellowship (SJF) award to him. Part of this work is towards achieving SJF project objectives.

Topical Editor F. D’ Andrea thanks three anonymous referees for their help in evaluating this paper.

\section{References}

Ackerman, A. S., Toon, O. B., Stevens, D. E., et al.: Reduction of tropical cloudiness by soot, Science, 288(5468), 1042-1047, 2000.

Andreae, M. O.: Aerosols before pollution, Science, 315, 50-51, 2007.

Asnani, G. C.: Tropical Meteorology, vols. 1 and 2, 1012 pp., Indian Inst. of Tropical Meteorol., Pashan, Pune, 1993.

Campbell, J. R., Welton, E. J., Spinhirne, J. D., Ji, Q., Tsay, S.-C., Piketh, S. J., Barenbrug, M., and Holben, B. N.: Micropulse lidar observations of tropospheric aerosols over northeastern South Africa during the ARREX and SAFARI 2000 dry season experiments, J. Geophys. Res., 108(D13), 8497, doi:10.1029/2002JD002563, 2003.

Chandra, S., Satheesh, S. K., and Srinivasan, J.: Can the state of mixing of black carbon aerosols explain the mystery of 'excess' atmospheric absorption?, Geophys. Res. Lett., 31(19), L19109, doi:10.1029/2004GL020662, 2004.

Dulac, F. and Chazette, P.: Airborne study of a multi-layer aerosol structure in the eastern Mediterranean observed with the airborne polarized lidar ALEX during a STAAARTE campaign (7 June 1997), Atmos. Chem. Phys., 3, 1817-1831, 2003, http://www.atmos-chem-phys.net/3/1817/2003/.

Gadhavi, H. and Jayaraman, A.: Airborne lidar study of the vertical distribution of aerosols over Hyderabad, an urban site in central India, and its implication for radiative forcing calculations, Ann. Geophys., 24, 2461-2470, 2006, http://www.ann-geophys.net/24/2461/2006/.

Heintzenberg, J. and Charlson, R. J.: Design and Applications of the Integrating Nephelometer: A Review, J. Atmos. Oceanic Technol., 13, 987-1000, 1997.

Intergovernmental Panel on Climate Change: Climate Change 1994: Radiative Forcing of Climate, Report to IPCC From the Scientific Assessment Group (WGI), Cambridge Univ. Press, New York, 2001. 
Jacobson, M. Z.: Strong radiative heating due to the mixing state of black carbon in atmospheric aerosols, Nature, 409(6821), 695697, 2001

Johnson, B. T., Heese, B., McFarlane, S. A., Chazette, P., Jones, A., and Bellouin, N.: Vertical distribution and radiative effects of mineral dust and biomass burning aerosol over West Africa during DABEX, J. Geophys. Res., 113, D00C12, doi:10.1029/2008JD009848, 2008.

King, M. D., Platnick, S., Moeller, C. C., Revercomb, H. E., and Chu, D. A.: Remote sensing of smoke, land and clouds from the NASA ER-2 during SAFARI-2000, J. Geophys. Res., 108(D13), 8502, doi:10.1029/2002JD003207, 2003.

Kirchstetter, T. W., Novakov, T., Hobbs, P. V., and Magi, B.: Airborne Measurements of Carbonaceous Aerosols in Southern Africa During the Dry Biomass Burning Season, J. Geophys. Res., 108(D13), 8476, doi:10.1029/2002JD002171, 2003.

Kovalev, V. A. and Eichinger, W. E.: Elastic Lidar: Theory, Practice and Analysis Methods, Wiley-Interscience, Hoboken, N. J., 2004.

Fernald, F. G.: Analysis of atmospheric lidar observations: Some comments, Appl. Optics, 23, 652-653, 1984.

Heese, B. and Wiegner, M.: Vertical aerosol profiles from Raman polarization lidar observations during the dry season AMMA field campaign, J. Geophys. Res., 113, D00C11, doi:10.1029/2007JD009487, 2008.

Krishnamurti, T. N., Jha, B., Prospero, J. M., et al.: Aerosol and pollutant transport and their impact on radiative forcing over the tropical Indian Ocean during the January-February 1996 preINDOEX cruise, Tellus-B, 50(5), 521-542, 1998.

Liou, K. N.: An Introduction to Atmospheric Radiation, Academic Press, 583 pp., 2002.

Maring, H., Savioe, D. L., Izaguirre, M. A., Custals, L., and Reid, J. S.: Vertical distributions of dust and sea-salt aerosols over Puerto Rico during PRIDE measured from a light aircraft, J. Geophys. Res., 108(D19), 8587, doi:10.1029/2002JD002544, 2003.

McGill, M. J., Hlavka, D. L., Hart, W. D., Welton, E. J., and Campbell, J. R.: Airborne lidar measurements of aerosol optical properties during SAFARI-2000, J. Geophys. Res., 108(D13), 8493, doi:10.1029/2002JD002370.

McGill, M. J., Vaughan, M. A. Trepte, C. R., Hart, W. D. Hlavka, D. L. Winker, D. M., and Kuehn, R.: Airborne validation of spatial properties measured by the CALIPSO lidar, J. Geophys. Res., 112, D20201, doi:10.1029/2007JD008768, 2007.

Menzies, R. T., Tratt, D. M., Spinhirne, J. D., and Hlavka, D. L.: Aerosol layers over the Pacific Ocean: Vertical distributions and optical properties as observed by multiwavelength airborne lidars, J. Geophys. Res., 107(D16), 4292, doi:10.1029/2001JD001196, 2002.

Moorthy, K. K. and Satheesh, S. K.: Characteristics of aerosols over a remote island, Minicoy in the Arabian Sea: Optical Properties and Retrieved Size Distributions, Q. J. Roy. Meteorol. Soc., 126, 81-109, 2000.

Moorthy, K. K., Babu, S. S., and Satheesh, S. K.: Aerosol spectral optical depths over the Bay of Bengal: Role of transport, Geophys. Res. Lett., 30(5), 1249, doi:10.1029/2002GL016520, 2003.

Moorthy, K. K., Babu, S. S., Sunilkumar, S. V., et al.: Altitude profiles of aerosol BC, derived from aircraft measurements over an inland urban location in India, Geophys. Res. Lett., 31(22),
L22103, doi:10.1029/2004GL021336, 2004.

Moorthy, K. K., Satheesh, S. K., Suresh Babu, S., and Dutt, C. B. S.: Integrated Campaign for Aerosols, gases and Radiation Budget (ICARB): An Overview, J. Earth Syst. Sci., 117(S1), 243-262, 2008.

Muller, D., Franke, K., Wagner, F., et al.: Vertical profiling of optical and physical particle properties over the tropical Indian Ocean with six-wavelength lidar 1. Seasonal cycle, J. Geophys. Res., 106(D22), 28567-28575, 2001.

Muller, D., Franke, K., Wagner, F., et al.: Vertical profiling of optical and physical particle properties over the tropical Indian Ocean with six-wavelength lidar 2. Case studies, J. Geophys. Res., 106(D22), 28577-28595, 2001.

Müller, D., Mattis, I., Wandinger, U., Ansmann, A., Althausen, D., Dubovik, O., Eckhardt, S., and Stohl, A.: Saharan dust over a central European EARLINET-AERONET site: Combined observations with Raman lidar and Sun photometer, J. Geophys. Res., 108(D12), 4345, doi:10.1029/2002JD002918, 2003.

Niranjan, K., Sreekanth, V., Madhavan, B. L., et al.: Wintertime aerosol characteristics at a north Indian site Kharagpur in the Indo-Gangetic plains located at the outflow region into Bay of Bengal, J. Geophys. Res., 111(D24), D24209, doi:10.1029/2006JD007635, 2006.

Niranjan, K., Sreekanth, V., Madhavan, B. L., et al.: Aerosol physical properties and Radiative forcing at the outflow region from the Indo-Gangetic plains during typical clear and hazy periods of wintertime, Geophys. Res. Lett., 34(19), L19805, doi:10.1029/2007GL031224, 2007.

Niranjan, K., Madhavan, B. L., and Sreekanth, V.: Micro pulse lidar observation of high altitude aerosol layers at Visakhapatnam located on the east coast of India, Geophys. Res. Lett., 34(3), L03815, doi:10.1029/2006GL028199, 2007.

Nyeki, S., Eleftheriadis, K., Baltensperger, U., Colbeck, I., Fiebig, M., Fix, A., Kiemle, C., Lazaridis, M., and Petzold, A.: Airborne Lidar and in-situ Aerosol Observations of an Elevated Layer, Leeward of the European Alps and Apennines, Geophys. Res. Lett., 29(17), 1852, doi:10.1029/2002GL014897, 2002.

Palm, S. P., Melfi, S. H., and Carter, D. L.: New airborne scanning lidar system: Applications for atmospheric remote sensing, Appl. Optics, 33, 5674-5681, 1994.

Pelon, J., Flamant, C., Chazette, P., et al.: Characterization of aerosol spatial distribution and optical properties over the Indian Ocean from airborne LIDAR and radiometry during INDOEX'99, J. Geophys. Res., 107(D19), 8029, doi:10.1029/2001JD000402, 2002.

Ramanathan, V., Crutzen, P. J., Lelieveld, J., et al.: Indian Ocean Experiment: An integrated analysis of the climate forcing and effects of the great Indo-Asian haze, J. Geophys. Res., 106(D22), 28371-28398, 2001.

Ramanathan, V., Ramana, M. V., Roberts, G., et al.: Warming trends in Asia amplified by brown cloud solar absorption, Nature, 448(7153), 575-578, 2007.

Satheesh, S. K., Ramanathan V., Xu, L. J., et al.: A model for the natural and anthropogenic aerosols over the tropical Indian Ocean derived from Indian Ocean Experiment data, J. Geophys. Res., 104(D22), 27421-27440, 1999.

Satheesh, S. K. and Ramanathan, V.: Large differences in tropical aerosol forcing at the top of the atmosphere and Earth's surface, Nature, 405(6782), 60-63, 2000. 
Satheesh, S. K.: Aerosol radiative forcing over land: effect of surface and cloud reflection, Ann. Geophys., 20, 2105-2109, 2002, http://www.ann-geophys.net/20/2105/2002/.

Satheesh, S. K.: Radiative forcing by aerosols over Bay of Bengal region, Geophys. Res. Lett, 29(22), 2083, doi:10.1029/2002GL015334, 2002.

Satheesh, S. K., Srinivasan, J., and Moorthy, K. K.: Spatial and temporal heterogeneity in aerosol properties and radiative forcing over Bay of Bengal: Sources and role of aerosol transport, J. Geophys. Res., 111(D8), D08202, doi:10.1029/2005JD006374, 2006a.

Satheesh, S. K., Vinoj, V., and Moorthy, K. K.: Vertical distribution of aerosols over an urban continental site in India inferred using a micro pulse lidar, Geophys. Res. Lett., 33(20), L20816, doi:10.1029/2006GL027729, 2006b.

Satheesh, S. K., Deepshikha, S., Srinivasan, J., and Kaufman, Y. J.: Large Dust Absorption of Infrared Radiation over Afro-Asian Regions: Evidence for Anthropogenic Impact, IEEE Geosci. Rem. Sens. Lett., 111, D08202, doi:10.1029/2005JD006374, 2006c.

Satheesh, S. K., Moorthy, K. K., Suresh Babu, S., Vinoj, V., and Dutt C. B. S.: Climate Implications of Large Warming by Elevated Aerosol over India, Geophys. Res. Lett., 35, L19809, doi:10.1029/2008GL034944, 2008.

Satheesh, S. K., Krishna Moorthy, K., Suresh Babu, S., Vinoj, V., Nair, V. S., Naseema Beegum, S., Dutt, C. B. S., Alappattu, D. P., and Kunhikrishnan, P. K.: Vertical structure and horizontal gradients of aerosol extinction coefficients over coastal India inferred from airborne lidar measurements during the Integrated Campaign for Aerosol, Gases and Radiation Budget (ICARB) field campaign, J. Geophys. Res., 114, D05204, doi:10.1029/2008JD011033, 2009.
Schmid, B., Redemann, J., Russell, P. B., et al.: Coordinated airborne, spaceborne, and ground-based measurements of massive thick aerosol layers during the dry season in southern Africa, J. Geophys. Res., 108(D13), 8496, doi:10.1029/2002JD002297, 2003.

Seinfeld, J.: Black carbon and brown clouds, Nature Geosci., 1, 15-16, 2008.

Spinhirne, J. D.: Micro Pulse Lidar. IEEE Trans. Geo. Rem. Sens., 31, 48-55, 1993.

Stull, R. B.: An Introduction into Boundary Layer Meteorology, Kluwer Academic Publishers, Dordrecht, Netherlands, 1999.

Vaughan, M. A., Young, S. A., Winker, D. M., Powell, K. A., Omar, A. H., Liu, Z., Hu, Y., and Hostetler, C. A.: Fully automated analysis of space-based lidar data: An overview of the CALIPSO retrieval algorithms and data products, Proc. SPIE Int. Soc. Opt. Eng., 5575, 16-30, 2004.

Welton, E. J., Voss, K. J., Quinn, P. K., et al.: Measurements of aerosol vertical profiles and optical properties during INDOEX 1999 using Micro-Pulse Lidars, J. Geophys. Res., 107(D19), 8019, doi:10.1029/2000JD000038, 2002.

Winker, D. M., Hunt, W. H., and McGill, M. J.: Initial performance assessment of CALIOP, Geophys. Res. Lett., 34, L19803, doi:10.1029/2007GL030135, 2007. 